\title{
On the heat transfer through roof tile coverings
}

\author{
Michele Bottarelli*, Marco Bortoloni \\ Dipartimento di Architettura, Università degli Studi di Ferrara, Ferrara 44121, Italy \\ Email: michele.bottarelli@unife.it
}

\begin{abstract}
In hot climates, ventilated pitched roofs with tiled coverings reduce the heat transfer across the roof, due to the ventilated air layer between tiles and roofing underlay, which is formed by the arrangement of battens and counter-battens. This so-called Above Sheathing Ventilation (ASV), which depends on the air entering and leaving at the eaves, ridge and the gaps between the tiles, has been enhanced by increasing the roof air permeability by means of novel roof tile shapes. This study analyses the air permeability improvement of a novel tile and its effect on the heat transfer induced by an external heat source (e.g. solar radiation). A CFD model is used to simulate the fluid flow and heat transfer through the tiles, solving the steady-state incompressible fluid flow in a $3 \mathrm{D}$ domain by means of the standard $\mathrm{k}-\varepsilon$ model. A parametric study is conducted to analyse the variation in the air flow passing through the tile and the tile temperature for different incident air flow conditions. A significant increase in flow rate is observed with the novel tile, which produces a lower temperature of the tile and of the air flowing through the tiles. This would help dissipating the excess heat in summer.
\end{abstract}

Keywords: Ventilated Roof, Above Sheathing Ventilation, Tile Air Permeability, CFD, Novel Tile Shapes.

\section{INTRODUCTION}

In hot climates, such as the Mediterranean regions, the energy demand for air-conditioning in summer represents a significant financial and environmental cost. According to the recent European environmental policies for improving the thermal performance of the building envelope, the use of ventilated roofs can significantly reduce the energy requirement for space cooling and increase the indoor thermal comfort [1].

In ventilated pitched roofs, the ventilated layer below the covering, which is usually recognised as the Above Sheathing Ventilation (ASV), helps to dissipate the excess heat gain (due to solar radiation) by increasing the natural and forced air convection. The arrangement of battens and counter-battens supporting the tiles allows an air flow below the covering, from the eaves to the ridge, as shown in Figure 1. In the case of discontinuous roof covering (e.g. roofing tiles), the ventilation is enhanced by the air permeability between the overlapping tiles, which provides an additional, distributed network of airflow paths in to and out of the ASV.

The summer performance of ventilated roofs in reducing solar heat gain has been investigated and highlighted by several studies. Real-scale models were prepared to run outdoor tests under real environmental condition in [2] and [3]. In [2], the summer performance of the ASV in combination with a radiant barrier was analysed. A significant daytime performance improvement was observed.
Different sizes of the ventilation duct are compared in [3].

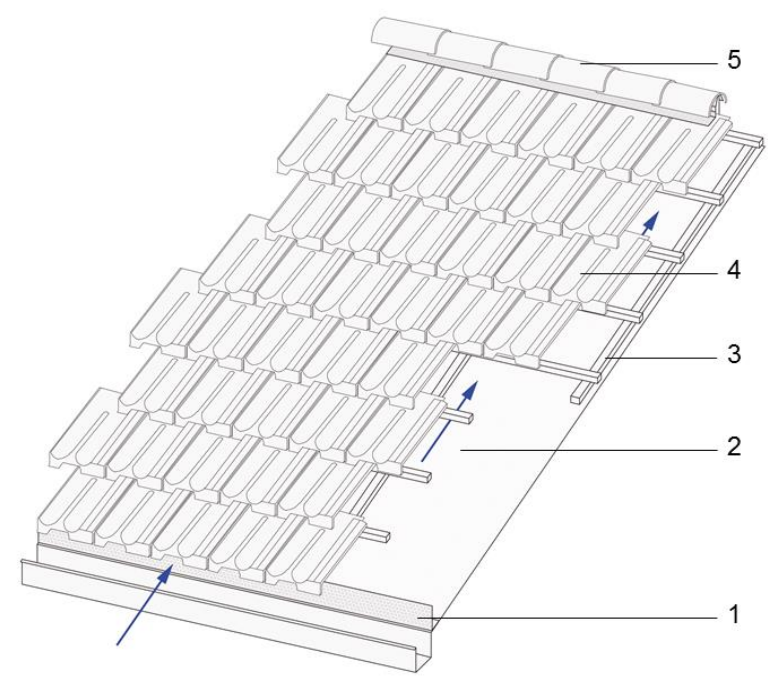

Figure 1. A ventilated pitched roof with a covering of Marseillaise tiles: 1) ventilated eaves; 2) ASV; 3) batten \& counter-batten; 4) roof tiles; 4) ventilated ridge

Six different types of passive roof were monitored during very hot summer days in India, [4]. The ventilated pitched roof with a covering of clay tiles showed the optimum indoor thermal performance. The reduction of solar heat gain of a 
ventilated concrete tile was investigated in [5], in comparison with an ordinary corrugated roof tile.

A scale model of a typical dwelling was used to monitor the thermal behaviour of a pitched roof with a covering in ceramic tiles and ventilated eaves, observing a significant heat dissipation capacity [6]. Laboratory tests are carried out to evaluate the airflow and the temperature distribution in an $\mathrm{ASV}$, as a function of the intensity of the solar radiation and the size and shape of the channel [7]. A correlation between solar radiation and ventilation rate, based on experimental data, was discussed in [8].

Other works followed a numerical approach to predict the air-flows and the heat transfer in ventilated roofs. Numerical simulations were carried out in [9] to quantify the thermal benefits of a tiled roof over a traditional shingle roof: a benefit of $14 \%$ was found. A numerical model was developed and validated against experimental data in [10]. According to this work, the air flow induced by the buoyancy forces within the ventilated space reduces the heat flux into the attic by $30 \%$ in comparison to a direct-nailed roof. Similar results were obtained in [11] by means of a steady state numerical simulation of ventilated and micro-ventilated roofs. The ventilated roof performance against that of a conventional roof were analysed in both summer and winter conditions in [12]. A simplified ventilated roof was modelled with FLUENT in [13], showing that the heat fluxes can be reduced up to $50 \%$ during summer. Recently, the natural convection due to buoyancy forces in ventilated roofs was simulated in [14] as a function of solar radiation in different thermal conditions (summer and winter season). Buoyancy forces are demonstrated to be efficient in producing significant airflows in the channel.

Most of the previous numerical simulations did not take into account the air permeability of a discontinuous covering (e.g. with roof tile) by modelling the ASV as an air duct. The effect of tile air permeability on the ASV was numerically investigated in [15] using a 2D CFD model of a ventilated roof equipped with simplified flat roof tiles. This work highlighted that the air permeability of the roof covering increases the mass flow rate along the ventilation channel improving also the thermal performance of the roof in reducing the solar heat gain in summer.

Taking the above into consideration, the ASV can be further enhanced by increasing the air permeability of a discontinuous covering, which is a characteristic tied to a specific tile geometry and it is intrinsically linked to the materials, manufacturing process and know-how of individual tile producer. The design of clay tiles can be improved to increase the air permeability, as proposed in the European project LIFE HEROTILE for two basic shapes: Portuguese and Marseillaise type (the second one is shown in Figure 1), which both are traditional styles widespread in the market of Southern Europe, easily recognizable for the original shapes with a "bold roll" and a "low profile", respectively.

As a part of these efforts, a CFD model, which was previously implemented and validated to provide an aid to tile design process in [16], has been furtherly detailed to analyse the air permeability of clay roof tiles and its effect on the heat transfer induced by an external heat source. For this purpose, the behaviour of a novel Marsellaise roof tile is analysed in comparison with that of an improved tile shape, which was specifically designed to enhance the ASV effect.
A parametric study of different incident air flow velocities and directions is conducted to simulate the incident wind on a real roof covering, with the aim of evaluating the variation in the air flow passing through the tile and the subsequent variation in the air and tile temperature.

\section{METHODOLOGY}

A numerical approach is followed to assess the roof tile air permeability and to predict the thermal behaviour of novel Marseillaise tile shapes (which were designed to enhance the flow rate between laid tiles), according to different external flow conditions (in terms of direction and intensity).

Two novel tile shapes are analysed and compared. Figure 2 shows the 3D model and the cross section of the improved shape project P2 (in grey), which is compared with the cross section of the basic project P1 (in red). The P2 improved design involves changes in the side-lock geometry, which is higher than in P1, to facilitate air intake when wind blows sideways. As a consequence, the labyrinthine path formed by the gap between tiles (i.e. the side-lock pattern) has been modified to yield the driving rain function.

The potential benefits of the improved design P2 over the basic one P1 are evaluated in terms of flow rate through the tiles (i.e. permeability to air) and of temperature of the air and of the tiles. The simulations are carried out by means of the commercial finite-element code COMSOL Multiphysics V5.2, by solving the thermo-fluid steady state problem in a 3D computational domain. The RANS-based standard k- $\varepsilon$ model is used in the hypothesis of an incompressible fluid.

In order to check the reliability of the numerical model, a preliminary testing activity was carried at Monier Technical Centre (Heusenstamm, Germany) with a dedicated test rig. The experiment consisted of sucking/blowing air down a pipe into a large wooden plenum on top of which was laid an array of the tiles under investigation. The testing procedure was compliant with the standard provided in [17]. The air permeability of a tile array built with an existing Marseillaise tile shape was evaluated using the pressure difference across the tiles at measured air flow rates.

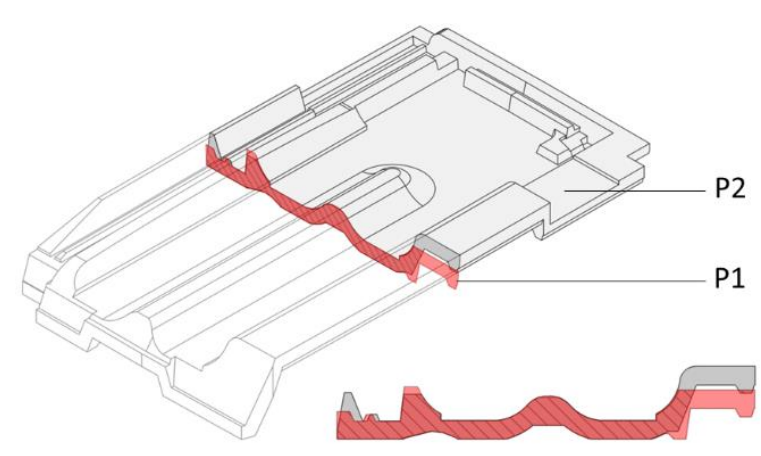

Figure 2. Modelled Marseillaise tiles: P1 basic design project; P2 improved design project

The results of air permeability tests have been used as the benchmark to calibrate the CFD model, which replicates the geometry and operation of the test rig. In the model, the vertical displacement between the overlapping tiles was considered as the calibration parameter to take into account of the gaps between the real tiles (due to distortion produced by drying and firing processes) which allows the air passing 
through them. More details about the testing activity and the calibration of the CFD model are presented in [16].

The calibrated model is here used as the basis to develop a more detailed model for analysing the thermal behaviour and the air permeability of the $\mathrm{P} 1$ project and its evolution $\mathrm{P} 2$, when subjected to an incident air flow and when heated up by a heat flux. A parametric approach is applied for the simulation by varying the inlet air velocity (from $0.5 \mathrm{~m} / \mathrm{s}$ to $1.5 \mathrm{~m} / \mathrm{s}$ ) which blows over the tiles with three angles, from the front $\left(0^{\circ}\right)$ to the side $\left(60^{\circ}\right)$.

\subsection{Numerical modelling}

The focus of the present work is to analyse the behaviour of roof tiles in terms of air permeability and how it affects its heat dissipation performance, at the expense of a simplification to the external fluid flow problem. The behaviour of a real ventilated roof in fact, can be affected by several different variables, such us the eaves overhang, the bird guards, the size of batten and counter-batten, which are not taken into account in this study. This analysis is set to support the design of innovative roof tiles for the future application in roof-tiles coverings improving the above sheathing ventilation.

The Non-Isothermal Flow interface of COMSOL Multiphysics V5.2a (based on finite element method) is used to simulate the incompressible fluid flows and the heat transfer in fluids, where the fluid properties (air in this case) depend on temperature. It is assumed that the fluid flow regime is steady state turbulent, viscous dissipations are negligible. The RANS-based standard k- $\varepsilon$ turbulence model is applied. The governing equations solved by the numerical model are conservation of energy, mass and momentum for the fluid part (air flow) and conservation of energy only for the solid part (the tile array through which the fluid flows).

In the numerical model, three-dimensional domains replicate the geometry of the test rig [16], which was built at the Monier Technical Centre, in terms of plenum and placement of the tiles. A scheme representing the cross section of the model domain is shown in Figure 3. The layout of the experimental setup has been simplified in the numerical domain only including an array of tiles, equivalent to the borders of the four tiles left unsealed on the test rig. The upper box of the test rig has been introduced as an upper air volume where the inlet boundary condition is set to simulate the incident velocity field over the tiles.

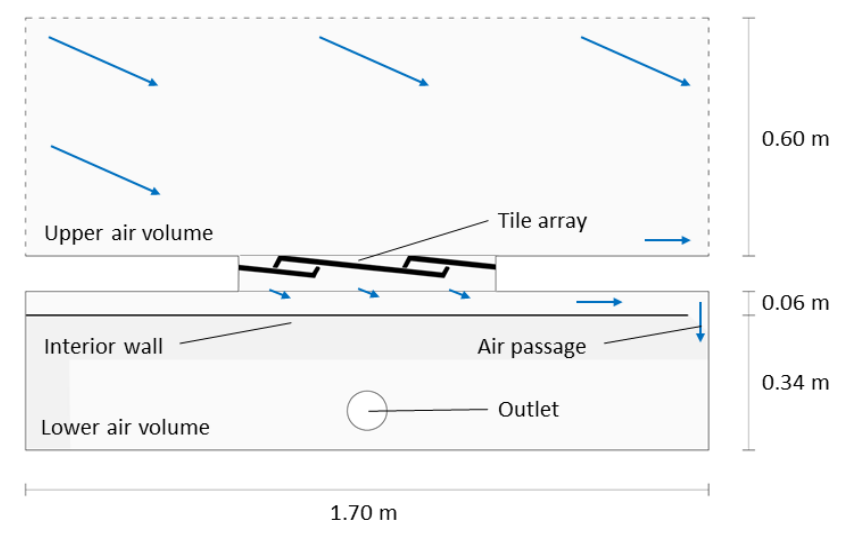

Figure 3. CFD model of the test rig: model domain
The air can flow from the upper volume to the lower one through a section which consists of the equivalent array of four tiles, in analogy to the $2 \times 2$ tile section left unsealed in the test rig. The air flows through the array of tiles into the lower air volume where a diaphragm was introduced to form a 6-cm high channel, with a hole in the terminal part. Consequently, the air flow is conveyed along a channel horizontally and parallel to the tiles (similarly to a ventilated roof), then move to the lower region towards the outlet. In the model, the diaphragm is reduced to an interior wall (no fluid penetration), which is set to a wall boundary condition to model the thin region with large gradients in flow variables, and it does not participate in heat transfer.

The P1 and P2 Marseillaise tile shape have been imported in two identical model domains from CAD drawings by means of the CAD Import Module. Each 3D tile model was subjected to a pre-processing phase in order to remove unnecessary details and surfaces features that can reduce control over the mesh sizing options.

In terms of boundary conditions, the model is set to simulate the non-isothermal fluid flow over and through a tile array heated up by an external heat source (the solar radiation in a real case).

In view of this, a heat flux of $400 \mathrm{~W} / \mathrm{m}^{2}$ is applied uniformly on the upper surface of the roof tiles. A uniform air velocity profile and a constant air temperature distribution $\left(20{ }^{\circ} \mathrm{C}\right)$ define the inlet boundary condition, which is set at three boundaries (two vertical and one horizontal surfaces) of the upper air volume of the box, as shown in red in Figure 4a. This arrangement is chosen because the air only blows from one side with an angle of incidence $\alpha\left(20^{\circ}\right)$, various directions $\beta\left(0^{\circ}, 30^{\circ}, 60^{\circ}\right)$ and intensities $(0.5,1.0,1.5 \mathrm{~m} / \mathrm{s})$. The air flow angle of incidence is set represent a typical pitch of a roof slope with a tiled covering. In the model, the three components of the velocity vector are defined as follows:

$\left\{\begin{array}{l}u=i \cdot \cos (\alpha) \cdot \cos (\beta) \\ v=i \cdot \cos (\alpha) \cdot \sin (\beta) \\ w=-i \cdot \sin (\alpha)\end{array}\right.$

where $i$ defines the intensity $(\mathrm{m} / \mathrm{s}), \alpha$ is the angle of incidence (deg), $\beta$ accounts the direction (deg), and $u, v, w$ detail the air flow velocity components in $x, y, z$ direction $(\mathrm{m} / \mathrm{s})$.

The air flows out from the outlet section, which is set at atmospheric pressure. The remaining boundary surfaces of the upper air volume (showed in red in Figure 4b) are open fluid and thermal boundary condition, so that the fluid can leave the domain or enter with a specified exterior temperature, which is set equal to the inlet temperature $\left(20^{\circ} \mathrm{C}\right)$. All other boundary surfaces were defined as no-slip walls (preparatory models showed surface roughness effects to be negligible).

Different mesh resolutions have been tested in order to produce reliable and mesh-independent results for both $\mathrm{P} 1$ and P2. The final mesh, shown in Figure 5 for the tiles section in the case P1, was considered an acceptable compromise between mesh resolution and time required for simulations. The whole mesh is composed of 840,000 elements which produces $1,560,000$ degrees of freedom. To improve the solution, a greater concentration of elements is imposed on the tile surfaces and within the interstices between tiles. This case in fact, is a multiscale problem; since the large scales, which are related to the interactions between the external airflow, are connected to the small scales 
associated with fluid flow the tiny interstices among the overlapping tiles (i.e. the permeability to air of tiles).

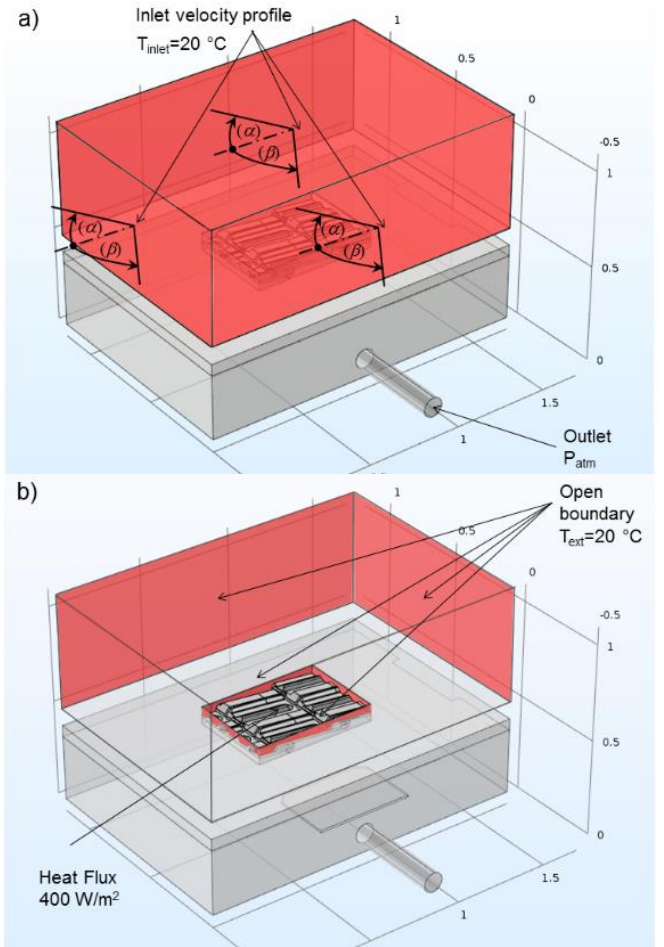

Figure 4. 3D model domain and main boundary conditions

\section{RESULTS AND DISCUSSION}

The aim of this study is to analyse the thermal and fluid behaviours of novel roof tiles, which have been designed to improve the air permeability of a ventilated roof covering. The P1 and P2 tile shapes are parametrically analysed simulating 9 incident air flow conditions: three air velocity $(i$ $=0.5,1.0,1.5 \mathrm{~m} / \mathrm{s})$ blowing over the tiles with three horizontal directions $\left(\alpha=0^{\circ}, 30^{\circ}, 60^{\circ}\right)$; the tiles are heated up by a heat flux, which is applied on the upper surface.

Figure 6 depicts the temperature distribution on the tile sections with $\mathrm{P} 1$ and $\mathrm{P} 2$ shapes. In addition, the fluid flow stream lines near the tile upper surface are shown when the air blows sideways over the tiles $\left(\beta=60^{\circ} ; i=1 \mathrm{~m} / \mathrm{s}\right)$, which represents a favourable condition for P2. Overall, the P2 tiles are slightly cooler than the $\mathrm{P} 1$, especially in the portions where the geometry has been modified. The sidelock in P2 is higher to have a larger opening exposed to the air flow when coming from the side, thus allowing more air to flow through the tiles.

The P1 and P2 tile shapes are compared in terms of mass flow rate (calculated at the outlet section) in Figure 7, according to the air flow velocity $(i)$ and directions $\left(0^{\circ}, 30^{\circ}\right.$, $\left.60^{\circ}\right)$. For both $\mathrm{P} 1$ and $\mathrm{P} 2$ the mass flow rate has a linear relationship with the air velocity.

A significant increase in the air permeability is observed in the case P2, which has always higher mass flow rates than the case P1. The difference increases as the angle of incidence $(\beta)$ moves from facing the tiles head-on $\left(0^{\circ}\right)$ to the side-on $\left(60^{\circ}\right)$; this can be mainly attributed to the improved design of the sidelock in P2 that act as intake vent. Contrary to $\mathrm{P} 2$, a decrease is shown for $\mathrm{P} 1$.

The improvement is significant, especially at lower wind intensities; P2 produces a mass flow rate increase of $14.5 \%$ and $13.7 \%$ when the air flows frontally with intensity of 0.5 $\mathrm{m} / \mathrm{s}$ and $1.5 \mathrm{~m} / \mathrm{s}$, respectively. The increase is $98.0 \%$ and $77.6 \%$ for a lateral air flow $\left(60^{\circ}\right)$.

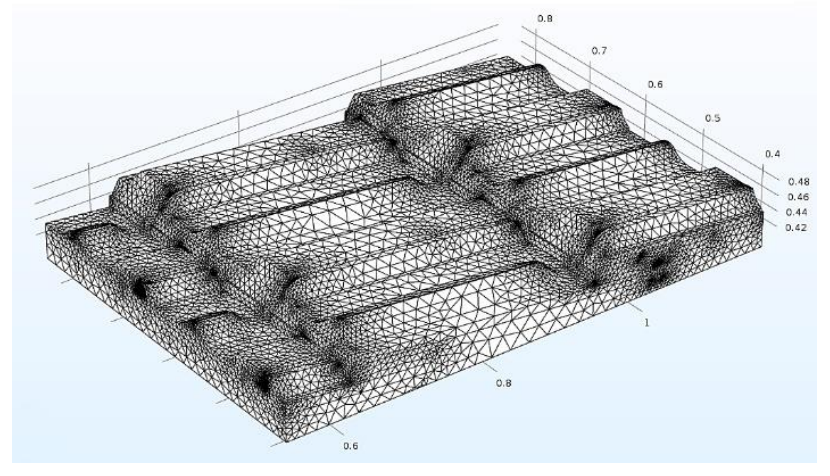

Figure 5. Detail of the tiles section and the mesh

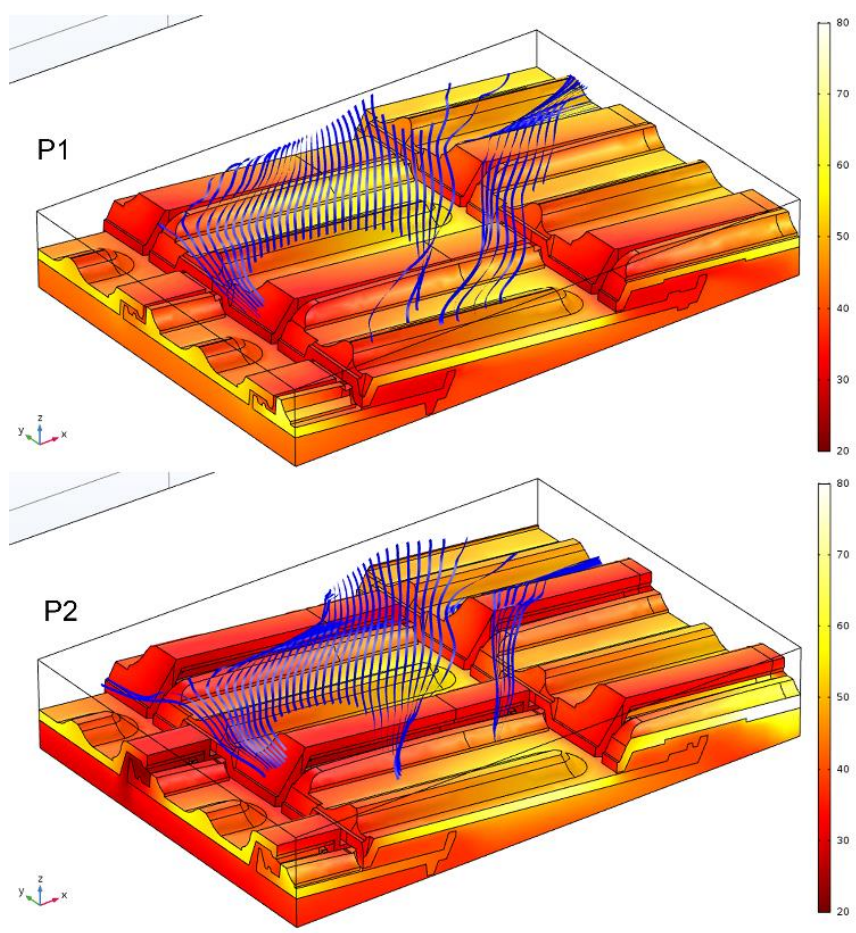

Figure 6. Temperature field on tiles section and air flow streamlines

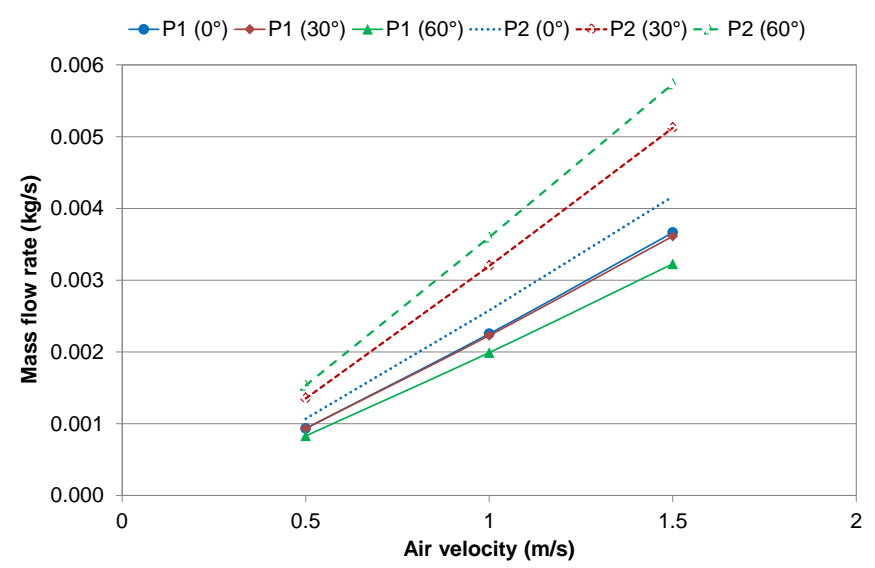

Figure 7. Air permeability as a function of air velocity 
Figure 8 presents the variation in the outlet temperature with respect to the air flow velocity $(i)$ for various directions $\left(0^{\circ}, 30^{\circ}, 60^{\circ}\right)$. The external air flow temperature (entering at $20^{\circ} \mathrm{C}$ ) increases by passing through the tiles array (which is heated up by the heat flux applied to the upper surface). This temperature can be considered to be representative of the air flowing into the ASV in a ventilated roof.

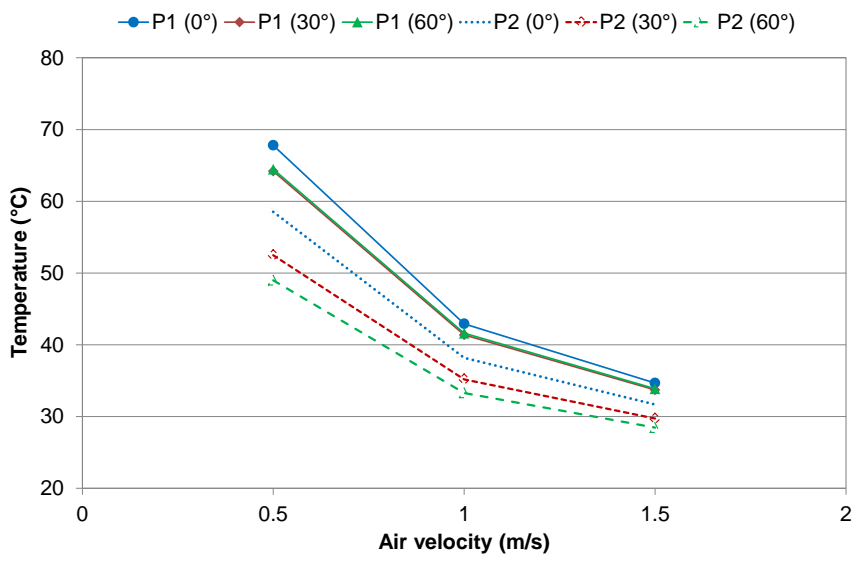

Figure 8. Air flow outlet temperature as a function of air velocity

The temperature decreases as the mass flow rate increases, according to air flow velocity and direction. The air temperature is always favourable in $\mathrm{P} 2$ case. At low velocity $\left(i=0.5 \mathrm{~m} / \mathrm{s}\right.$ ) the temperature in $\mathrm{P} 2$ case is $9.8{ }^{\circ} \mathrm{C}$ lower than in $\mathrm{P} 1$ when the air flows from to the front; the difference increases to $16^{\circ} \mathrm{C}$ for $\beta=60^{\circ}$.

Finally, in Figure 9, P1 and P2 shapes are compared in terms of variation in tile temperature (calculated as the average of the tile array) according to the air flow directions. In a ventilated roof, the tile temperature is an important parameter that affects the radiative heat transfer between the roof covering and the underlying structure. In view of this, major benefits are expected during the summer season for lower tile temperature values. In both cases, a significant decrease in the tile temperature is calculated as the air flow increased. According to previous results, the P2 case shows on average colder tile temperature than $\mathrm{P} 1$, from a maximum difference of $7{ }^{\circ} \mathrm{C}$ to a minimum of $2{ }^{\circ} \mathrm{C}$.

\section{SUMMARY AND CONCLUSIONS}

A numerical investigation is carried aiming to analyse the roof tile air permeability and to predict the thermal behaviour of two novel Marseillaise tile shapes according to different external flow conditions. The objective of this preliminary analysis is to provide an aid to the design process of innovative tile shapes. Two novel Marseillaise tiles have been designed to increase the tile air permeability and consequently to enhance the effectiveness of the ASV in reducing heat gains through the roof due to solar radiation.

A CFD model, which was previously implemented, has been furtherly detailed to solve the heat transfer and turbulent fluid flow problem in a steady state regime. The numerical domain is a replica of the experimental rig in terms of geometry and operation, which was used to test the air permeability of existing tiles. The results of the testing activity have been used as the benchmark to calibrate the
CFD model. A parametric study of different incident air flow velocities and directions is conducted to analyse the behaviour of the two novel tiles in terms of permeability to air and variation in the air and tile temperature.

The improved tile shape allows a significant increase in the air permeability up to $100 \%$ in comparison to the basic project one. The difference between the two tile shapes is higher at low air velocities. In addition, when the wind direction moves from directly facing the tile array to coming in from the side the new design of the sidelock produces an increase in the air flow rate. In view of this, an increase in the ASV is expected by installing the innovative tile as the discontinuous covering element in ventilated roofs.

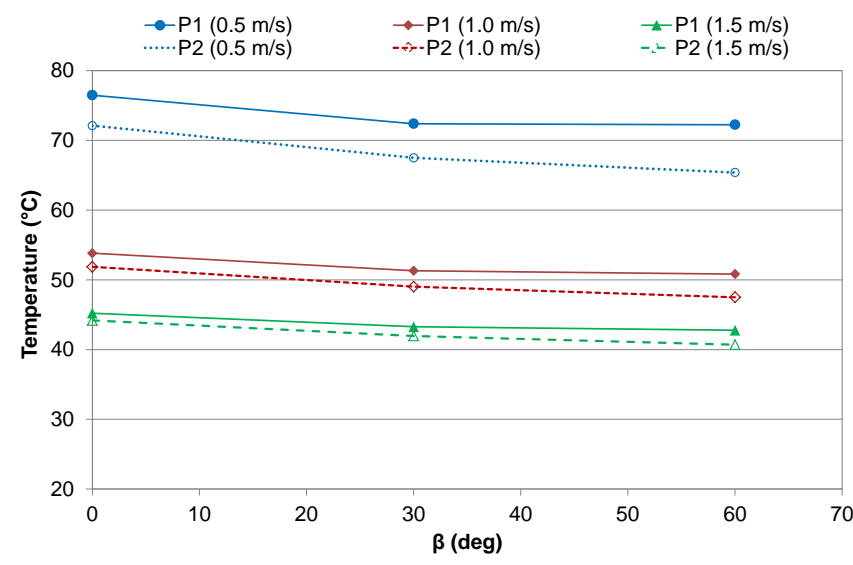

Figure 9. Tile temperature as a function of air flow direction

The increase in the mass flow rate through the tile array positively affects the temperature of the air flowing into the ASV, as well as the temperature of the tiles, which are both significantly lower in the case of the improved shape project.

Since ventilation layer in pitched roofs is recognized as an effective solution in reducing the solar heat gain in summer a further performance improvement can be expected with the use of high permeability tiles.

\section{ACKNOWLEDGMENT}

Work on the HEROTILE project (LIFE14 CCA/IT/000939) "High Energy savings in building cooling by ROof TILEs shape optimization toward a better above sheathing ventilation", is funded by the EU LIFE "Climate Change Adaptation" programme and the other project partners. More information about the project can be found at http://www.lifeherotile.eu/.

\section{REFERENCES}

[1] Patania F., Gagliano A., Nocera F., Ferlito A., Galesi A. (2011). Energy analysis of ventilated roof, Sustainability in Energy and Buildings. Smart Innovation, Systems and Technologies, Vol. 7, Howlett R.J., Jain L.C., Lee S.H. (Eds), Springer, Berlin, Germany, pp. 15-23. DOI: 10.1007/978-3-642-17387$\underline{52}$

[2] Dimoudi A., Androutsopoulos A., Lykoudis S. (2006). Summer performance of a ventilated roof component, 
Energy and Buildings, Vol. 38, No. 6, pp. 610-617. DOI: $\underline{10.1016 / j . e n b u i l d .2005 .09 .006}$

[3] D’Orazio M., Di Perna C., Principi P., Stazi A. (2008). Effects of roof tile permeability on the thermal performance of ventilated roofs: Analysis of annual performance, Energy and Buildings, Vol. 40, pp. 911916. DOI: $10.1016 /$ j.enbuild.2007.07.003

[4] Madhymathi A., Radhakrishnan S., Shanthi P.R. (2014). Sustainable roofs for warm humid climates A case study in residential buildings in Madurai, Tamilnadu, India, World App. Sc. J., Vol. 32, pp. 1167-1180. DOI: 10.5829/idosi.wasj.2014.32.06.1261

[5] Amornleetrakul O., Puangsombut W., Hirunlabh J. (2014). Field investigation of the small house with the ventilated roof tiles, Advanced Materials Research, Vol. 931-932, pp. 1233-1237. DOI: 10.4028/www.scientific.net/AMR.931-932.1233

[6] Ramos J., Almeida L., Pitarma R. (2015). Experimental study on a naturally ventilated ceramic tile roof as potentially beneficial for the thermal performance of housing, Materials and Technologies for Energy Efficiency, Méndez-Vilas A. (Eds.), Brown Walker Press, Boca Raton, pp. 208-212.

[7] Lee S., Park S.H., Yeo M.S., Kim K.W. (2009). An experimental study on airflow in the cavity of a ventilated roof, Building and Environment, Vol. 44, pp. 1431-1439. DOI: 10.1016/j.buildenv.2008.09.009

[8] Sandberg M., Moshfegh B. (1998). Ventilated-solar roof airflow and heat transfer investigation, Renewable Energy, Vol. 15, pp. 287-292. DOI: 10.1016/S09601481(98)00175-X

[9] De W., Cherry N., Haig J. (2009). Thermal benefits of tiled roofs with above-sheathing ventilation, Int. J. of Building Physics, Vol. 33, pp. 171-194. DOI: 10.1177/1744259109105238

[10] Miller W., Keyhani M., Stovall T., Youngquist A. (2007). Natural convection heat transfer in roofs with above-sheathing ventilation, Thermal Performance of the Exterior Envelopes of Buildings X, Ashrae Therm $\mathrm{X}$, Clearwater Beach.

[11] Ciampi M., Leccese F., Tuoni F. (2005). Energy analysis of ventilated and microventilated roofs, Solar
Energy, Vol. 79, No. 2, pp. 183-192. DOI: 10.1016/j.solener.2004.08.014

[12] Villi G., Pasut W., De Carli M. (2009). CFD modelling and thermal performance analysis of a wooden ventilated roof structure, Build. Simul., Vol. 2, pp. 215-228. DOI: $10.1007 / \mathrm{s} 12273-009-9414-7$

[13] Gagliano A., Patania F., Nocera A.F., Galesi A. (2012). Thermal performance of ventilated roofs during summer period, Energy and Buildings, Vol. 49, pp. 611-618. DOI: 10.1016/j.enbuild.2012.03.007

[14] Bianco V., Diana A., Manca O., Nardini S. (2016). Thermal behavior evaluation of ventilated roof under variable solar radiation, Int. J. of Heat and Technology, Vol. 34, pp. 346-350. DOI: 10.18280/ijht.34S222

[15] Bortoloni M., Bottarelli M., Piva S. (2017). Summer thermal performance of ventilated roofs with tiled coverings, IOP Conf. Series: J. of Physics: Conf. Series, No. 796. DOI: $10.1088 / 1742-$ 6596/796/1/012023

[16] Bottarelli M., Bortoloni M., Zannoni G., Allen R., Cherry (2017). CFD analysis of roof tile coverings, Energy. DOI: 10.1016/ j.energy.2017.03.081

[17] Slating and tiling for pitched roofs and vertical cladding - Code of practice. (2014). BS 5534, UK.

\section{NOMENCLATURE}

$\begin{array}{ll}\mathrm{P} 1 & \text { basic project shape } \\ \mathrm{P} 2 & \text { improved project shape } \\ u & \text { air flow component in } \mathrm{x} \text { direction, } \mathrm{m} / \mathrm{s} \\ v & \text { air flow component in y direction, } \mathrm{m} / \mathrm{s} \\ w & \text { air flow component in } \mathrm{z} \text { direction, } \mathrm{m} / \mathrm{s} \\ i & \text { air flow intensity, } \mathrm{m} / \mathrm{s}\end{array}$

\section{Greek symbols}

$\alpha$

air flow angle of incidence, deg air flow direction, deg 